\title{
Sublimation enthalpies at 298.15 K using correlation gas chromatography and differential scanning calorimetry measurements
}

\author{
James Chickos*, Donald Hesse, Sarah Hosseini, Gary Nichols, Paul Webb \\ Department of Chemistry, University of Missouri-St. Louis, St. Louis, MO 63121, USA
}

Received 20 June 1997; received in revised form 10 November 1997; accepted 11 November 1997

\begin{abstract}
The sublimation enthalpies of 17 hydrocarbons are obtained by combining the technique of correlation gas chromatography (CGC), to evaluate vaporization enthalpies at $298.15 \mathrm{~K}$, and differential scanning calorimetry (DSC) to measure fusion enthalpies. Vaporization enthalpies at $298.15 \mathrm{~K}$ obtained by CGC are compared to values measured directly from vapor pressure measurements at temperatures above the melting point by adjusting the experimental vaporization enthalpy for the effects of temperature. Vaporization enthalpies obtained by these two methods agree within $\pm 3877 \mathrm{~J} \mathrm{~mol}^{-1}$. Fusion enthalpies are similarly adjusted for temperature. Sublimation enthalpies, obtained by combining temperature adjusted fusion, and vaporization enthalpies agree within $\pm 2580 \mathrm{~J} \mathrm{~mol}^{-1}$. The sublimation enthalpies of azulene and 1,8-cyclotetradecadiyne are also measured by head-space analysis resulting in values of 76880 and $94348 \mathrm{~J} \mathrm{~mol}^{-1}$ at $298.15 \mathrm{~K}$, respectively. (C) 1998 Elsevier Science B.V.
\end{abstract}

Keywords: Correlation gas chromatography; Sublimation enthalpy; Vaporization enthalpy

\section{Introduction}

Sublimation enthalpies are an important macroscopic measure of the magnitude of intermolecular interactions in the solid state [1]. A variety of experimental techniques have been developed to measure sublimation enthalpies. These include measurements of mass transport by means of gas saturation techniques, Knudsen and torsion effusion, head-space analysis and calorimetry [2]. Many of these techniques require both, sophisticated equipment and highly trained personnel or involve measurements that are

\footnotetext{
*Corresponding author. Fax: 001314516 5342; e-mail: jscums1@jinx.umsl.edu
}

time-consuming and labor-intensive. Recently, we documented how a simple gas chromatographic technique could be used to obtain enthalpies of vaporization at $298.15 \mathrm{~K}$ [3]. We have now applied this technique to a series of 17 solid hydrocarbons, and have obtained vaporization enthalpies for these solids at $298.15 \mathrm{~K}$. Combining these vaporization enthalpies with experimental fusion enthalpies adjusted to $298.15 \mathrm{~K}$, using a protocol recently described, results in reliable sublimation enthalpies [4]. This report illustrates how this protocol can be applied to obtain accurate sublimation enthalpies. Included in the 17 hydrocarbons are two compounds with reported sublimation enthalpies of questionable value. The sublimation enthalpy of these two compounds are measured both by DSC-CGC and head-space analysis. 


\section{Theoretical}

\subsection{Sublimation enthalpies}

Accurate measurements of sublimation enthalpy can be obtained by combining the results of Eq. (1) with those of Eqs. (2) and (3) [4]. Eq. (1) is a thermodynamic equality which provides accurate sublimation enthalpies at the melting point of a solid, $T_{\text {fus }}$. Vaporization enthalpies can be adjusted from $298.15 \mathrm{~K}$ to $T_{\text {fus }}$ by using Eq. (2). The sublimation enthalpy obtained at $T_{\text {fus }}$, can then be adjusted back to $298.15 \mathrm{~K}$ by using Eq. (3) as has been documented recently $[4,5]$ :

$$
\begin{aligned}
& \Delta_{\text {sub }} H_{\mathrm{m}}\left(T_{\text {fus }}\right)=\Delta_{\text {vap }} H_{\mathrm{m}}\left(T_{\text {fus }}\right)+\Delta_{\text {fus }} H_{\mathrm{m}}\left(T_{\text {fus }}\right) \\
& \Delta_{\text {vap }} H_{\mathrm{m}}\left(T_{\text {fus }}\right)=\Delta_{\text {vap }} H_{\mathrm{m}}(298.15 \mathrm{~K}) \\
& \quad+\left[10.58+0.26 C_{\text {Pl estd }}(298.15 \mathrm{~K})\right] \\
& \quad \times\left(298.15-T_{\text {fus }}\right) \\
& \quad \Delta_{\text {sub }} H_{\mathrm{m}}(298.15 \mathrm{~K})=\Delta_{\text {sub }} H_{\mathrm{m}}\left(T_{\text {fus }}\right) \\
& \quad+\left[0.75+0.15 C_{\text {Pc estd }}(298.15)\right] \\
& \quad \times\left(T_{\text {fus }}-298.15\right)
\end{aligned}
$$

The symbols $C_{\mathrm{Pl}}$ estd and $C_{\mathrm{Pc}}$ estd in Eqs. (2) and (3) refer to the heat capacities of the liquid and solid phases of the compound in question at $298.15 \mathrm{~K}$ and can be estimated by group additivity [6]. The reliability of Eqs. (1)-(3) has been tested against experimental data. Sublimation enthalpies obtained by using Eqs. (1)-(3) have been compared to results measured directed for a series of 117 compounds. A standard deviation of $\pm 4210 \mathrm{~J} \mathrm{~mol}^{-1}$ was observed between experimental sublimation enthalpies measured directly and those obtained through the use of Eqs. (1)-(3) [4].

\subsection{Correlation gas chromatography and head space analysis}

Gas chromatography has previously been used to measure thermodynamic properties of solutions. Recently, we reported a simple modification of a technique used by Peacock and Fuchs [7] to obtain vaporization enthalpies of a variety of simple organic molecules including hydrocarbons. The procedure has been detailed previously [3]. A brief outline is provided below, using the data in Table 1 as an example.

Included among the compounds measured previously [3] were a few hydrocarbons that are solids at $298.15 \mathrm{~K}$. If the retention time measured by the gas chromatograph is inversely proportional to the vapor pressure of the solute in solution on the stationary phase of the column, then the enthalpy of transfer $\left(\Delta_{\mathrm{sln}}^{v} H_{\mathrm{m}}(\bar{T})\right)$ that is measured from a study of the temperature dependence of retention time should be independent of the physical state of the material at $298.15 \mathrm{~K}$. Correlation of $\Delta_{\mathrm{sln}}^{v} H_{\mathrm{m}}(\bar{T})$ with the $\Delta_{\mathrm{vap}} H_{\mathrm{m}}^{0}$ $(298.15 \mathrm{~K})$ of the compounds with known vaporization enthalpies should provide reasonable values of $\Delta_{\text {vap }} H_{\mathrm{m}}^{0}(298.15 \mathrm{~K})$ for the solids whose vaporization enthalpies at $298.15 \mathrm{~K}$ are presumably unknown, provided both, retention times and vaporization enthalpies are properly bracketed by the standards [3].

Vaporization enthalpies at $298.15 \mathrm{~K}$, obtained for the liquid state of solids, when added to their respective fusion enthalpies corrected to $298.15 \mathrm{~K}$ result in reasonable estimates of their sublimation enthalpies $[3,4,8]$. We would now like to report the application of

\begin{tabular}{|c|c|c|c|c|c|c|}
\hline Compound & 220 & 230 & 240 & 250 & 260 & 270 \\
\hline $\mathrm{CCl}_{4}$ & 2.70 & 2.726 & 2.747 & 2.77 & 2.804 & 2.833 \\
\hline Hexadecane & 3.853 & 3.622 & 3.467 & 3.354 & 3.266 & 3.211 \\
\hline trans-Stilbene & 4.785 & 4.354 & 4.044 & 3.817 & 3.642 & 3.52 \\
\hline Anthracene & 5.70 & 5.069 & 4.607 & 4.269 & 4.006 & 3.818 \\
\hline Eicosane & 7.331 & 6.110 & 5.259 & 4.679 & 4.256 & 3.965 \\
\hline Docosane & 11.822 & 9.179 & 7.38 & 6.186 & 5.340 & 4.761 \\
\hline
\end{tabular}
this technique using the protocol described above (Eqs. (1)-(3)) to evaluate the sublimation enthalpy of a total of 17 solid hydrocarbons. It should be emphasized that the vaporization enthalpies of these

Table 1

Retention time $(\min )$ at $\mathrm{T}^{\circ} \mathrm{C}$ 
solids obtained by correlation gas chromatography can be hypothetical yet thermodynamically relevant numbers, as shown below. This is demonstrated in a number of cases where the vaporization enthalpy of the liquid state of the solid is available in the literature at temperatures above the melting point. Adjustment of the vaporization enthalpy from some mean temperature of measurement, $\bar{T}$, to $298.15 \mathrm{~K}$ using Eq. (2) gives good agreement with the value measured by correlation gas chromatography. Combination of the vaporization enthalpy with the corresponding fusion enthalpy, according to the protocol defined by Eqs. (1)-(3), results in a sublimation enthalpy which compares very favorably to the value measured directly [4].

In addition to using literature values for comparison of sublimation enthalpies, obtained by the combined DSC-CGC method, we would also like to report the sublimation enthalpies of 1,8-cyclotetradecadiyne and azulene measured directly by head-space analysis. Measurement of the sublimation enthalpy of 1,8cyclotetradecadiyne has been repeated because of a large discrepancy observed between the value, calculated using Eqs. (1)-(3) (94348 $\mathrm{J} \mathrm{mol}^{-1}$, Table 6) and the literature value of $\left(166000 \mathrm{~J} \mathrm{~mol}^{-1}\right.$, [9]). The sublimation enthalpy of azulene has been reported several times. These enthalpies are summarized in Table 5. For a molecule with many physical properties markedly similar to naphthalene, a standard in sublimation calorimetry, agreement between three out of the four reported values is quite poor. This prompted us to measure this value again, both by head-space analysis and by the combined protocol of DSC-CGC and associated Eqs. (1)-(3). The results of using the combined protocol of DSC-CGC for both 1,8-cyclotetradecadiyne and azulene are reported in Table 6.

\section{Experimental}

\subsection{Instrumentation and procedure-correlation gas chromatography}

All the gas chromatographic experiments described here were performed on a Hewlett-Packard Model 5890 Series II Gas Chromatograph equipped with a split/splitless capillary injection port and a flameionization detector. The column temperature was monitored independently using a Kluke $51 \mathrm{~K} / \mathrm{J}$ thermometer. Additional details of the equipment and of the procedure have been described previously [3]. Retention-time data for the 17 compounds listed in Table 6 along with the standards used have been reported $[3,8,10]$. Some data are included in Table 1 and the protocol used in treating the data is discussed below. Results for the seventeen compounds listed in Tables 5 and 6 are in most instances averages of a variety of experiments, some from duplicate runs, others from experiments performed under different conditions of temperature, column and internal standards (various $n$-alkanes). Typical columns used include the following: $30 \mathrm{~m}$ DB-5, $60 \mathrm{~m}$ DB-5MS, and a $30 \mathrm{~m}$ HP-1 column. The standard deviations associated with the reproducibility of the experiments reported in the second column of Table 5 varied from 300 to $700 \mathrm{~J} \mathrm{~mol}^{-1}$. The literature values used for the $n$-alkanes $\mathrm{C}_{10}-\mathrm{C}_{20}$ are those recently recommended by Ruzicka and Majer [11] and, for $\mathrm{C}_{21}-\mathrm{C}_{28}$, those recommended by Chickos and Wilson [12].

\subsection{Instrumentation and procedure-head-space analysis}

The procedure used in head-space analysis has been detailed previously [2]. 1,8-Cyclotetradecadiyne, purchased from $\mathrm{K}$ and $\mathrm{K}$ Laboratories was recrystallized from acetone, $\mathrm{mp} 96.7-97.3^{\circ} \mathrm{C}$ ([9]). The sample was assayed as $99.93 \%$ pure by gas chromatography on a $5 \mathrm{~m} \times 0.53 \mathrm{~mm}$ DB-1 Megabore capillary column. Two impurities with longer retention times were also observed. ${ }^{1} \mathrm{H}$ and ${ }^{13} \mathrm{C}$ NMR confirmed both the chemical composition and purity of the sample. An infrared spectrometer, a PE Model 783 equipped with a data station was used in these experiments. Absorbances were calibrated with prepared standard solutions of 1,8-cyclotetradecadiyne in a matched set of $0.2 \mathrm{~mm} \mathrm{NaCl}$ solution cells by measuring the absorbance at $2927 \mathrm{~cm}^{-1}$ relative to the baseline at $3050 \mathrm{~cm}^{-1}$ in carbon tetrachloride. Sixteen values of vapor pressures, varying from 0.6 to $55 \mathrm{~Pa}$, were measured over the $315-364 \mathrm{~K}$ range. It is important to recognize that while the temperature dependence of the vapor pressure measured by head-space analysis is reliable, the actual value of the vapor pressures is not, and vapor pressures as determined by head-space analysis should be considered only as approximate 
values. The results are shown in columns $1-4$ of Table 3.

A sample of azulene, kindly provided to us by Professor William Herndon, was determined to be $99.46 \%$ pure as assayed by gas chromatography on a $30 \mathrm{~m} \times 0.32 \mathrm{~mm}$ DB-5 capillary column, $\mathrm{mp} 99.2$ $100^{\circ} \mathrm{C}\left(99-100.5^{\circ} \mathrm{C}[18]\right)$. It was observed that three impurities eluted later than azulene. Vapor pressures were determined by a quantitative infrared analysis of the condensed vapors trapped from the steady-state head-space experiments in carbon tetrachloride. A Perkin-Elmer Model 1600 FTIR was used in the analysis. Absorbances were calibrated with prepared standard solutions of azulene in a single $0.2 \mathrm{~mm} \mathrm{NaCl}$ solution cell by measuring the net absorbance at $1392 \mathrm{~cm}^{-1}$ and the baseline at $1350 \mathrm{~cm}^{-1}$. Measurements were made on 16 vapor-pressure values over the $283.3-325.6 \mathrm{~K}$ range, resulting in vapor pressures in the $0.3-25$ Pa range. The results are shown in columns 5-8 of Table 3.

\subsection{Differential scanning calorimetry}

Fusion enthalpies were determined on a PerkinElmer Model DSC-2 differential scanning calorimeter interfaced to a computer and calibrated with indium metal $\left(28700 \pm 330 \mathrm{~J} \mathrm{~mol}^{-1}\right.$ [23]). All analyses were performed in triplicate. The fusion enthalpy of azulene measured in a standard aluminum sample pan was $19200 \pm 500 \mathrm{~J} \mathrm{~mol}^{-1}$. Upon reweighing the sample, a 3-8\% weight loss was detected. Repetition of this set of experiments using stainless-steel high-pressure capsules (PE B018-2901) resulted in a value of $17530 \pm 800 \mathrm{~J} \mathrm{~mol}^{-1}$ with no detectable weight loss. Similarly, for adamantane, a fusion enthalpy of $10910 \pm 800 \mathrm{~J} \mathrm{~mol}^{-1}$ was measured using the high pressure cells.

\section{Results and discussion}

\subsection{Vaporization enthalpies of trans-stilbene and anthracene}

In the correlation gas chromatography experiments, the dead volume of the column is generally obtained by measuring the retention time of an unretained component injected in the mixture. In the experiments described in Table 1, the solvent carbon tetrachloride is not retained on the column and its retention time is used for this measurement. As the temperature is increased, the viscosity of the helium carrier gas increases and the flow rate decreases, thereby increasing the retention time of carbon tetrachloride $\left(r t_{\mathrm{CCl}_{4}}\right)$. Differences in the retention time of the hydrocarbons relative to that of carbon tetrachloride measure the amount of time spent by the solute on the column. This time is inversely proportional the vapor pressure of the solute in solution. A plot of $\ln \left(1 /\left(r t_{\text {solute }}-r t_{\mathrm{CCl}_{4}}\right)\right.$ against $1 / T$ $\left(\mathrm{K}^{-1}\right)$ results in a straight line as characterized by the correlation coefficient, $r^{2}$, given in the third column of Table 2. Correlation coefficients of less than 0.99 are usually an indication of some retention of the component used to measure the dead volume. The slope of the line multiplied by the gas-constant results in the enthalpy of transfer from solution to the vapor, $\Delta_{\sin }^{v} H_{\mathrm{m}}$, column 2 of Table 2 . A second correlation between $\Delta_{\mathrm{vap}} H_{\mathrm{m}}^{0}(298.15 \mathrm{~K})$ and, columns 2 and 4 of Table 2, results in Eq. (4). This relationship is used to evaluate the vaporization enthalpies of the unknowns. The vaporization enthalpies reported for trans-stilbene and anthracene in Table 2 are derived from Eq. (4); those reported in Tables 4 and 6 are averages of several determinations by gas chromatography.

Table 2

Enthalpies (in $\mathrm{J} \mathrm{mol}^{-1}$ )

\begin{tabular}{lllll}
\hline Compound & $\Delta_{\mathrm{s} \ln }^{\mathrm{v}} H_{\mathrm{m}}$ & $\begin{array}{l}\text { Correlation coefficient } \\
r^{2}\end{array}$ & $\begin{array}{l}\Delta_{\mathrm{vap}} H_{\mathrm{m}}^{0}(298.15 \mathrm{~K}) \\
\text { (lit) }\end{array}$ & $\begin{array}{l}\Delta_{\mathrm{vap}} H_{\mathrm{m}}^{0}(298.15 \mathrm{~K}) \\
(\mathrm{calc})\end{array}$ \\
\hline Hexadecane & 49467 & 0.9996 & 81400 & 80860 \\
Eicosane & 62759 & 0.9999 & 101800 & 103444 \\
Docosane & 69265 & 0.9999 & 115600 & 114496 \\
trans-Stilbene & 49381 & 0.9999 & & 80713 \\
Anthracene & 49571 & 0.9998 & & 81036 \\
\hline
\end{tabular}




$$
\begin{aligned}
& \Delta_{\mathrm{vap}} H_{\mathrm{m}}^{0}(298.15 \mathrm{~K})=1.699( \pm 0.144) \\
& \quad \times \Delta_{\mathrm{sln}}^{v} H_{\mathrm{m}}(518.2 \mathrm{~K})-3188( \pm 2050) \\
& r^{2}=0.9929
\end{aligned}
$$

\subsection{Sublimation enthalpies of 1,8 - cyclotetradecadiyne and azulene}

The sublimation enthalpies of 1,8-cyclotetradecadiyne and azulene were obtained from a ClausiusClapeyron treatment of the data in Tables 1 and 3. A plot of $\ln$ (vapor pressure) against $1 / T\left(\mathrm{~K}^{-1}\right)$ resulted in Eqs. (5) and (6) for 1,8-cyclotetradecadiyne and azulene, respectively.

$$
\begin{gathered}
\ln P=-10535(1 / T)+33.0 ; \quad r^{2}=0.9972 ; \\
\Delta_{\mathrm{sub}} H_{\mathrm{m}}(338)=87580 \pm 1000 \mathrm{~J} \mathrm{~mol}^{-1} \\
\ln P=-9434(1 / T)+32.22 ; \quad r^{2}=0.9979 \\
\Delta_{\mathrm{sub}} H_{\mathrm{m}}(303)=78430 \pm 1300 \mathrm{~J} \mathrm{~mol}^{-1}
\end{gathered}
$$

This resulted in sublimation enthalpies of 89410 and $78550 \mathrm{~J} \mathrm{~mol}^{-1}$ for 1,8-cyclotetradecadiyne and azulene when the results were adjusted to $298.15 \mathrm{~K}$ using Eq. (3). Sublimation enthalpies obtained by headspace analysis are accurate to within $\pm 5 \%$ and, generally, result in values a few $\%$ lower than those obtained by other techniques [2].

The sublimation enthalpy of $89410 \mathrm{~J} \mathrm{~mol}^{-1}$ $(298.15 \mathrm{~K})$ for 1,8 -cyclotetradecadiyne measured in this work is considerably smaller than the value of $166000 \mathrm{~J} \mathrm{~mol}^{-1}$ reported previously [9]. A similar discrepancy has been noted for the value reported for cyclotetradecane [9,14,31]. The result of $78550 \mathrm{~J} \mathrm{~mol}^{-1}(298.15 \mathrm{~K})$ for azulene is in good agreement with two of the four values reported previously and suggest that the sublimation enthalpy is slightly larger than the value accepted for naphthalene. This is consistent with the more polar nature associated with the structure of azulene. These results along with other literature values are summarized in Table 5 and compared to the DSC-CGC results in Table 6.

\subsection{Vaporization enthalpies of solids by correlation gas chromatography}

Many of the solids selected to test the DSC-CGC

\begin{tabular}{|c|c|c|c|c|c|c|c|}
\hline \multicolumn{4}{|c|}{ 1,8-Cyclotetradecadiyne } & \multicolumn{4}{|l|}{ Azulene } \\
\hline $\begin{array}{l}\text { Sample temp./ } \\
\mathrm{K}\end{array}$ & $\begin{array}{l}\text { Bulb temp./ } \\
\mathrm{K}\end{array}$ & $\begin{array}{l}\text { Sample size/ } \\
\text { mg }\end{array}$ & $\begin{array}{l}\text { Vapor pressure/ } \\
\mathrm{Pa}\end{array}$ & $\begin{array}{l}\text { Sample temp./ } \\
\mathrm{K}\end{array}$ & $\begin{array}{l}\text { Bulb temp./ } \\
\text { K }\end{array}$ & $\begin{array}{l}\text { Sample size/ } \\
\text { mg }\end{array}$ & $\begin{array}{l}\text { Vapor pressure/ } \\
\mathrm{Pa}\end{array}$ \\
\hline 315.2 & 397 & 0.438 & 0.62 & 283.3 & 379 & 0.163 & 0.342 \\
\hline 323.2 & 397 & 0.939 & 1.33 & 283.4 & 379 & 0.149 & 0.314 \\
\hline 323.2 & 398 & 1.018 & 1.446 & 283.9 & 379 & 0.184 & 0.388 \\
\hline 323.2 & 398 & 0.977 & 1.387 & 293.4 & 381 & 0.511 & 1.081 \\
\hline 330 & 399 & 2.283 & 3.392 & 293.5 & 381 & 0.430 & 0.909 \\
\hline 330 & 399 & 2.331 & 3.318 & 293.6 & 379 & 0.597 & 1.256 \\
\hline 330 & 399 & 2.286 & 3.255 & 293.6 & 379 & 0.512 & 1.077 \\
\hline 343 & 400 & 6.088 & 8.677 & 303.3 & 369 & 1.470 & 3.013 \\
\hline 343 & 400 & 6.876 & 9.801 & 303.4 & 372 & 1.595 & 3.297 \\
\hline 353.1 & 401 & 16.37 & 23.43 & 303.4 & 377 & 1.520 & 3.185 \\
\hline 353.1 & 402 & 16.69 & 23.93 & 315.8 & 379 & 5.365 & 11.3 \\
\hline 353.2 & 403 & 17.53 & 25.21 & 315.8 & 379 & 4.903 & 10.33 \\
\hline 363.8 & 403 & 38.03 & 54.69 & 316 & 379 & 5.121 & 10.78 \\
\hline 363.8 & 404 & 38.57 & 55.5 & 324.8 & 381 & 11.00 & 23.25 \\
\hline \multirow[t]{2}{*}{363.8} & 404 & 38.53 & 55.51 & 325.1 & 381 & 11.17 & 23.64 \\
\hline & & & & 325.6 & 381 & 11.89 & 25.17 \\
\hline
\end{tabular}
results were chosen because vaporization and/or sublimation enthalpies are readily available. All vaporization enthalpies were calculated from vaporpressure measurements performed at temperatures

Table 3

Vapor pressure of 1,8-cyclotetradecadiyne and azulene as a function of temperature as determined by head-space analysis 
Table 4

Vaporization enthalpies of a series of solid hydrocarbons

\begin{tabular}{|c|c|c|c|c|}
\hline Compound & $\begin{array}{l}\Delta_{\text {vap }} H_{\mathrm{m}}^{0}(298.15 \mathrm{~K}) \text { by } \mathrm{GC} / \\
\left(\mathrm{J} \mathrm{mol}^{-1}\right)\end{array}$ & $\begin{array}{l}\Delta_{\mathrm{vap}} H_{\mathrm{m}}^{0}(\bar{T}) / \\
\left(\mathrm{J} \mathrm{mol}^{-1}\right)(\bar{T} / \mathrm{K}) \text { lit. }^{\text {a }}\end{array}$ & $\begin{array}{l}C_{\mathrm{Pl} \text { estd }} / \\
\left(\mathrm{J} \mathrm{mol}^{-1} \mathrm{~K}^{-1}\right)\end{array}$ & $\begin{array}{l}\Delta_{\text {vap }} H_{\mathrm{m}}^{0}(298.15 \mathrm{~K}) / \\
\left(\mathrm{J} \mathrm{mol}^{-1}\right) \text { lit. }\end{array}$ \\
\hline$\overline{\mathrm{C}_{10} \mathrm{H}_{8} \text { azulene }}$ & 58192 & $52999(384)$ & 205 & 58483 \\
\hline $\mathrm{C}_{10} \mathrm{H}_{8}$ naphthalene & 53438 & $50647(367)$ & 205 & 55045 \\
\hline $\mathrm{C}_{12} \mathrm{H}_{10}$ biphenyl & 66244 & $57275(405)$ & 249 & 65312 \\
\hline $\mathrm{C}_{12} \mathrm{H}_{10}$ acenaphthene & 66210 & $60342(383)$ & 244 & 66618 \\
\hline $\mathrm{C}_{12} \mathrm{H}_{24}$ cyclododecane & 63017 & $52576(401)$ & 311 & 61975 \\
\hline $\mathrm{C}_{13} \mathrm{H}_{10}$ fluorene & 72340 & $54229(417)$ & 282 & 63567 \\
\hline $\mathrm{C}_{14} \mathrm{H}_{10}$ anthracene & 79812 & $58568(519)$ & 279 & 76936 \\
\hline $\mathrm{C}_{14} \mathrm{H}_{10}$ phenanthrene & 78650 & $69617(388)$ & 279 & 77090 \\
\hline $\mathrm{C}_{14} \mathrm{H}_{12}$ trans-stilbene & 79725 & $65458(434)$ & 304 & 77640 \\
\hline $\mathrm{C}_{19} \mathrm{H}_{16}$ triphenylmethane & 94552 & $58601(527)$ & 395 & 84551 \\
\hline $\mathrm{C}_{24} \mathrm{H}_{18}$ 1,3,5-triphenylbenzene & 139950 & $118000(477)^{\mathrm{b}}$ & 484 & 142408 \\
\hline
\end{tabular}

${ }^{a}$ Ref. [20], unless noted otherwise.

${ }^{\mathrm{b}}$ Ref. [22].

above the melting point of the solid. Most vaporization enthalpies were calculated from the Antoine Constants by a Clausius-Clapyeron treatment of vapor pressure with temperature. A temperature range of $30 \mathrm{~K}$ was used. Vaporization enthalpies were adjusted to $298.15 \mathrm{~K}$, using Eq. (2), by replacing $T_{\text {fus }}$ and terms associated with $T_{\text {fus }}$ with values appropriate to the mean temperature, $\bar{T}$. Table 4 summarizes the vaporization enthalpy results. The vaporization enthalpies in column 2 are the values obtained by correlation gas chromatography. Literature values at temperature $\bar{T}$ (in parenthesis), are included in column 3 and were adjusted to $298.15 \mathrm{~K}$ using the estimated heat capacity of the liquid given in column 4 . The adjusted values are listed in column 5. Comparison of the values in columns 2 and 5 results in a standard deviation of $\pm 3877 \mathrm{~J} \mathrm{~mol}^{-1}$ between the two sets of numbers. The agreement between the results obtained by CGC and the literature is very good, considering the necessary temperature extrapolations.

\subsection{Sublimation enthalpies using DSC-correlation gas chromatography}

Compounds chosen to test the accuracy of $\Delta_{\text {sub }} H_{\mathrm{m}}$ $(298.15 \mathrm{~K})$ measured by DSC-CGC were selected because of the availability and reliability of their sublimation enthalpies. These values are summarized in Table 5. This table includes sublimation enthalpy values available in the literature and identifies how experimental values were selected for the comparisons that follow. All sublimation enthalpies reported at temperatures other than $298.15 \mathrm{~K}$ have been adjusted to $298.15 \mathrm{~K}$ using Eq. (3) by replacing $T_{\text {fus }}$ and terms associated with $T_{\text {fus }}$ with values appropriate to the mean temperature of measurement, $\bar{T}$. The heat capacities used for each temperature adjustment were estimated. The $C_{\mathrm{Pc}}$ estd $(298.15)$ values used for each of the compounds in Table 5 are included in Table 6.

Sublimation enthalpies obtained by the combined technique of CGC-DSC and associated equations can be compared to direct experimental measurements in Table 6. The second column of the table lists the vaporization enthalpies measured by correlation gas chromatography. The experimental fusion enthalpy for each compound is listed in column 3 followed by its melting point. The estimated heat capacities used in Eqs. (2) and (3) follow in the next two columns [6].

The sublimation enthalpy calculated according to Eqs. (1)-(3) is listed in column 7 and the experimental sublimation enthalpy obtained from Table 5 is listed in the last column. A comparison of these two columns results in a standard deviation of $\pm 2580 \mathrm{~J} \mathrm{~mol}^{-1}$. This uncertainty is similar to the uncertainty generated by a direct comparison of the experimental literature values in Table 5 and suggests that the protocol described by combining CGC with DSC, and adjusting the resulting enthalpies for temperature is equally useful for obtaining reliable sublimation enthalpies. 
Table 5

Recommended sublimation enthalpies of selected hydrocarbons at $298.15 \mathrm{~K}$

\begin{tabular}{|c|c|c|c|c|c|}
\hline \multicolumn{3}{|l|}{ Compound } & \multicolumn{3}{|l|}{ Compound } \\
\hline $\begin{array}{l}\text { Literature } \\
\text { value }\left[\text { Ref.] }{ }^{\text {a }}\right.\end{array}$ & Value selected & Comments & $\begin{array}{l}\text { Literature } \\
\text { value }\left[\text { Ref.] }{ }^{\text {a }}\right.\end{array}$ & Value selected & Comments \\
\hline \multicolumn{3}{|l|}{ tri-t-butylmethane } & \multicolumn{3}{|l|}{ acenaphthylene } \\
\hline $58600[8]$ & $57820 \pm 1110$ & Average of first & $73330[18]$ & $72510 \pm 1150$ & Average of all entries; \\
\hline $57030[16]$ & & two entries & $73000[19]$ & & recommended value \\
\hline $7700[17]$ & & & $71200[20]$ & & \\
\hline \multicolumn{3}{|l|}{ azulene } & \multicolumn{3}{|l|}{ trans-stilbene } \\
\hline $82900[20]$ & $76880 \pm 1630$ & Average of second, & $104400[26]$ & $102400 \pm 1870$ & Average of top three entries; \\
\hline $78550^{b}$ & & third and fourth entries & $100700[27]$ & & recommended value \\
\hline $75300[21]$ & & & $102100[28]$ & & \\
\hline $76800[19]$ & & & 61100 [29] & & \\
\hline $95400[25]$ & & & $99200[19]$ & & \\
\hline \multicolumn{3}{|l|}{ naphthalene } & \multicolumn{3}{|c|}{ 1,8-cyclotetradecadiyne } \\
\hline $72600[30]$ & $72600 \pm 300$ & $\begin{array}{l}\text { IUPAC } \\
\text { recommendation }\end{array}$ & $\begin{array}{l}166000[9] \\
89410^{\mathrm{b}}\end{array}$ & $89410 \pm 1000$ & This work \\
\hline \multicolumn{3}{|l|}{ cyclotetradecane } & \multicolumn{3}{|l|}{ acenaphthene } \\
\hline $98520[14]$ & $92170 \pm 5500$ & Average of first, & $86940[18]$ & $85310 \pm 1580$ & Average of all entries; \\
\hline $134950[9]$ & & third and fourth entries & 83400 [33] & & recommended value \\
\hline $89300[31]$ & & & $86200[34]$ & & \\
\hline $88700[32]$ & & & $84700[35]$ & & \\
\hline \multicolumn{3}{|l|}{ diphenylacetylene } & \multicolumn{3}{|l|}{ triphenylmethane } \\
\hline $95100[36]$ & $95100 \pm 1100$ & First Entry & $116390[39]$ & $112320 \pm 5800$ & Average of top two entries \\
\hline $90000[37]$ & & & $108250[40]$ & & \\
\hline $88700[38]$ & & & 101860 [41] & & \\
\hline \multicolumn{3}{|l|}{ fluorene $^{\mathrm{c}}$} & \multicolumn{3}{|l|}{ adamantane } \\
\hline $81500[42]$ & $86130 \pm 2170$ & Average of last & $58450[47]$ & $58810 \pm 2090$ & Average of all entries \\
\hline $80200[43]$ & & three entries & $60540[48]$ & & recommended value \\
\hline $92880[44]$ & & & $60140[49]$ & & \\
\hline $88600[18]$ & & & $54800[50]$ & & \\
\hline $85300[46]$ & & & $59300[51]$ & & \\
\hline $84500[46]$ & & & $59600[52]$ & & \\
\hline \multicolumn{3}{|l|}{ anthracene } & \multicolumn{3}{|l|}{ phenanthrene } \\
\hline $100240[53]$ & $99220 \pm 2910$ & Average of all entries & $90900[57]$ & $91810 \pm 2140$ & Average of all entries \\
\hline $103880[44]$ & & & $95160[18]$ & & \\
\hline $96800[54]$ & & & $92500[58]$ & & \\
\hline $97400[55]$ & & & 89570 [33] & & \\
\hline $97800[56]$ & & & $90900[19]$ & & \\
\hline \multicolumn{3}{|l|}{ cyclododecane } & \multicolumn{3}{|l|}{ biphenyl } \\
\hline \multirow[t]{4}{*}{$76400[59]$} & $76400 \pm 1400$ & Only value & $83780[39]$ & $82030 \pm 1210$ & Average of all entries \\
\hline & & & $81500[13]$ & & \\
\hline & & & $81020[48]$ & & \\
\hline & & & $81800[19]$ & & \\
\hline \multicolumn{6}{|c|}{ 1,3,5-triphenylbenzene } \\
\hline $152000[22]$ & $149545 \pm 1893$ & Average of all entries & & & \\
\hline \multicolumn{6}{|l|}{$149700[45]$} \\
\hline \multicolumn{6}{|l|}{$147430[24]$} \\
\hline $149070[20]$ & & & & & \\
\hline
\end{tabular}

\footnotetext{
${ }^{\mathrm{a}}$ All enthalpies: $\mathrm{J} \mathrm{mol}^{-1}$ at $298.15 \mathrm{~K}$.

${ }^{\mathrm{b}}$ Head-space analysis, this work.

${ }^{\mathrm{c}}$ Only the most recent five or six references were used.
} 
Table 6

Comparison of experimental sublimation enthalpies with values determined by combined DSC-CGC

\begin{tabular}{|c|c|c|c|c|c|c|c|}
\hline Compound & $\begin{array}{l}\Delta_{\mathrm{vap}} H_{\mathrm{m}} \\
(298.15 \mathrm{~K}) / \\
\left(\mathrm{J} \mathrm{mol}^{-1}\right)\end{array}$ & $\begin{array}{l}\Delta_{\text {fus }} H_{\mathrm{m}}{ }^{\mathrm{a}} / \\
\left(\mathrm{J} \mathrm{mol}^{-1}\right)\end{array}$ & $\begin{array}{l}T_{\text {fus }} l \\
\mathrm{~K}\end{array}$ & $\begin{array}{l}C_{\mathrm{Pc} \text { estd }} \mathrm{f} / \\
\left(\mathrm{J} \mathrm{mol}^{-1} \mathrm{~K}^{-1}\right)\end{array}$ & $\begin{array}{l}C_{\mathrm{Pl} \mathrm{estd}} \mathrm{f} / \\
\left(\mathrm{J} \mathrm{mol}^{-1} \mathrm{~K}^{-1}\right)\end{array}$ & $\begin{array}{l}\Delta_{\text {sub }} H_{\mathrm{m}}(298.15 \mathrm{~K}) / \\
\text { (from Eqs. (1)-(3)) }\end{array}$ & (from Table 4) \\
\hline$\overline{\mathrm{C}_{10} \mathrm{H}_{8} \text { azulene }}$ & 58192 & $17530^{b}$ & 374 & 157 & 205 & 72731 & 76880 \\
\hline $\mathrm{C}_{10} \mathrm{H}_{8}$ naphthalene & 53438 & 19100 & 353 & 157 & 205 & 70367 & 72600 \\
\hline $\mathrm{C}_{10} \mathrm{H}_{16}$ adamantane & 52007 & $10910^{b}$ & 541 & 194 & 238 & 52569 & 58810 \\
\hline $\mathrm{C}_{12} \mathrm{H}_{8}$ acenaphthylene & 64344 & 6940 & 327 & 171 & 236 & 69970 & 72510 \\
\hline $\mathrm{C}_{12} \mathrm{H}_{10}$ acenaphthene & 66210 & 21460 & 366 & 188 & 244 & 84612 & 85350 \\
\hline $\mathrm{C}_{12} \mathrm{H}_{10}$ biphenyl & 66244 & 18660 & 342 & 192 & 249 & 82897 & 82030 \\
\hline $\mathrm{C}_{12} \mathrm{H}_{24}$ cyclododecane & 63017 & $14800^{c}$ & 334 & 295 & 311 & 76152 & 76400 \\
\hline $\mathrm{C}_{13} \mathrm{H}_{10}$ fluorene & 72340 & 19580 & 388 & 199 & 262 & 87599 & 86130 \\
\hline $\mathrm{C}_{13} \mathrm{H}_{28}$ tri-t-butylmethane & 55859 & $3100^{\mathrm{d}}$ & 357 & 323 & 379 & 55433 & 57820 \\
\hline $\mathrm{C}_{14} \mathrm{H}_{10}$ diphenylacetylene & 76815 & 20502 & 334 & 223 & 306 & 95312 & 95100 \\
\hline $\mathrm{C}_{14} \mathrm{H}_{10}$ phenanthrene & 78650 & 15720 & 374 & 209 & 279 & 90500 & 91810 \\
\hline $\mathrm{C}_{14} \mathrm{H}_{10}$ anthracene & 79812 & 29372 & 489 & 209 & 279 & 99447 & 99220 \\
\hline $\mathrm{C}_{14} \mathrm{H}_{12}$ trans-stilbene & 79725 & 27600 & 398 & 235 & 304 & 101971 & 102400 \\
\hline $\mathrm{C}_{14} \mathrm{H}_{20} 1,8$-cyclotetradecadiyne & 75784 & 22600 & 370 & 303 & 353 & 94349 & 89410 \\
\hline $\mathrm{C}_{14} \mathrm{H}_{28}$ cyclotetradecane & 68459 & 28700 & 328 & 344 & 363 & 95589 & 92170 \\
\hline $\mathrm{C}_{19} \mathrm{H}_{16}$ triphenylmethane & 94552 & 21979 & 365 & 297 & 395 & 111987 & 112320 \\
\hline $\mathrm{C}_{24} \mathrm{H}_{18}$ 1,3,5-triphenylbenzene & 139950 & $22928^{\mathrm{e}}$ & 446 & 366 & 484 & 150936 & 149545 \\
\hline
\end{tabular}

${ }^{a}$ Fusion enthalpies are from Ref. [15], unless noted otherwise.

$\mathrm{b}$ This work.

${ }^{\mathrm{c}}$ From Ref. [60].

${ }^{\mathrm{d}}$ From Ref. [17].

${ }^{\mathrm{e}}$ From Ref. [22].

${ }^{\mathrm{f}}$ From Ref. [6].

The sublimation enthalpy of adamantane requires some additional comment. It has previously been shown that extrapolations using Eqs. (2) and (3) are valid from 200 to $500 \mathrm{~K}$ [4]. Since melting point of adamantane is $541 \mathrm{~K}$, temperature adjustments using these two equations for this compound are likely to be less reliable.

\section{Summary}

The sublimation enthalpies obtained by head-space analysis and combined DSC-CGC for both, 1,8-cyclotetradecadiyne and azulene are in good agreement with each other. The agreement obtained confirms that the literature value for reported for 1,8-cyclotetradecadiyne is in error. The value measured for azulene by head-space analysis, $78850 \mathrm{~J} \mathrm{~mol}^{-1}$, compares quite favorably with two of the literature values. A mean value of $76880 \mathrm{~J} \mathrm{~mol}^{-1}$ was selected on this basis. The value measured by the combined CGC-
DSC of $72731 \mathrm{~J} \mathrm{~mol}^{-1}$ is somewhat less than this but the results obtained for both 1,8-cyclotetradecadiyne and azulene are within the $\pm 4200 \mathrm{~J} \mathrm{~mol}^{-1}$ accuracy that characterizes this protocol [4].

The results of these experiments demonstrate the applicability of the combined DSC-CGC technique on hydrocarbons. In principle, this method should work equally as well for any class of compounds shown to give reliable vaporization enthalpies by CGC [3]. Advantages of the method include small sample requirements and ease of measurement. The protocol described above accommodates measurements performed at different temperatures, including the use of hypothetical as well as actual phase change enthalpies.

\section{Acknowledgements}

Financial support from the Research Board of the University of Missouri is gratefully acknowledged. 


\section{References}

[1] A. Gavezzotti, J. Amer. Chem. Soc. 111 (1989) 1835; A. Gavezzotti, J. Phys. Chem. 95 (1991) 8948; A. Gavezzotti, G. Filippini, Acta Crystallogr. B48 (1992) 537; A. Gavezzotti, G. Filippini, Acta Chim. Hung. 130 (1993) 205; A. Gavezzotti, G. Filippini, J. Phys. Chem. 98 (1994) 4831.

[2] J.S. Chickos, in: J.F. Liebman, A. Greenberg (Eds.), Molecular Structure and Energetics, Vol. 2, VCH Publishers, New York, 1987, Chap. 3.

[3] J.S. Chickos, S. Hosseini, D.G. Hesse, Thermochim. Acta 249 (1995) 41.

[4] J.S. Chickos, Thermochim. Acta 313 (1998) 19.

[5] J.S. Chickos, S. Hosseini, D.G. Hesse, J.F. Liebman, Structural Chem. 4 (1993) 271.

[6] J.S. Chickos, D.G. Hesse, J.F. Liebman, Structural Chem. 4 (1993) 261.

[7] L.A. Peacock, R. Fuchs, J. Amer. Chem. Soc. 99 (1977) 5524; R. Fuchs, L.A. Peacock, Can. J. Chem. 56 (1978) 2493; 57 (1979) 2302; 58 (1980) 2796; R. Fuchs, W.K. Stephenson, Can. J. Chem. 63 (1985) 349; R. Fuchs, E.J. Chambers, W.K. Stephenson, Can. J. Chem. 65 (1987) 2624.

[8] J.S. Chickos, D.G. Hesse, S. Hosseini, J.F. Liebman, G.D. Mendenhall, S.P. Verevkin, K. Rakus, H.-D. Beckhaus, C. Rüchardt, J. Chem. Thermodyn. 27 (1995) 693.

[9] M.A. Frisch, R.G. Bautista, J.L. Margrave, C.G. Parsons, J. Wotiz, J. Amer. Chem. Soc. 86 (1964) 335.

[10] Tables [A-11]-[A-20] in the Appendix of the Ph.D. Thesis of S. Hosseini, University of Missouri, St. Louis, 1995.

[11] K. Ruzicka, V. Majer, J. Phys. Chem. Ref. Data 23 (1994) 1.

[12] J.S. Chickos, J. Wilson, J. Chem. Eng. Data 42 (1996) 190.

[13] R.D. Chirico, S.E. Kripmeyer, A. Nguyen, W.V. Steele, J. Chem. Thermodyn. 21 (1989) 1307.

[14] J.S. Chickos, D.G. Hesse, S.Y. Panshin, D.W. Rogers, M. Saunders, P.M. Uffer, J.F. Liebman, J. Org. Chem. 57 (1992) 1897.

[15] E.S. Domalski, E.D. Hearing, J. Phys. Chem. Ref. Data, 25 (1996) 1; 19 (1990) 881; 13 (1984) suppl. 1.

[16] S.P. Verevkin, M. Nölke, H.-D. Beckhaus, C. Rüchardt, J. Org. Chem. 62 (1997) 4683.

[17] M.A. Flamm-ter Meer, H.-D. Beckhaus, C. Rüchardt, Thermochim. Acta 107 (1986) 331.

[18] W.J. Sonnefeld, W.H. Zoller, W.E. May, Anal. Chem. 55 (1983) 275.

[19] E. Morawetz, J. Chem. Thermodyn. 4 (1972) 455.

[20] R.M. Stephenson, S. Malanowski, Handbook of the Thermodynamics of Organic Compounds, Elsevier, New York, 1987, The sublimation enthalpy was calculated from the Antoine Constants and corrected to $298.15 \mathrm{~K}$ using Eq. (3).

[21] H. Hoyer, W. Peperle, Z. Electrochem. 62 (1958) 61.

[22] L. Malaspina, G. Bardi, R. Gigli, J. Chem. Thermodyn. 6 (1974) 1053.

[23] F. Groenvold, J. Therm. Anal. 13 (1978) 419.

[24] N. Wakayama, H. Inokuchi, Bull. Chem. Soc. Jpn. 40 (1967) 2267.
[25] A. Bauder, H.H. Gunthard, Helv. Chim. Acta (1962) 1698.

[26] G. Kratt, H.-D. Bechhaus, W. Bernlohr, C. Rüchardt, Thermochim. Acta 62 (1983) 279.

[27] P.J. Van Ekeren, M.H.G. Jacobs, J.C.A. Offringa, C.J. DeKruif, J. Chem. Thermodyn. 15 (1983) 409.

[28] C.G. DeKruif, H.A. Oonk, J. Chem. Ing. Techn. 45 (1973) 455; Chem. Abstr. 78 (1973) 152-198.

[29] J.R. Majer, A.S.P. Azzouz, J. Chem. Soc. Faraday Trans. I 79 (1983) 675

[30] K.N. Marsh (Ed.), IUPAC-Recommended Reference Materials for the Realization of Physicochemical Properties, Blackwell Scientific Publications, Oxford, UK, 1987.

[31] E.L. Eliel, J.J. Engelsman, J. Chem. Educ. 73 (1996) 903-905.

[32] J.J. Engelsman, Ph.D. Thesis, Vrije Universiteit Te Amsterdam, 1955

[33] A.G. Osborn, D.R. Douslin, J. Chem. Eng. Data 20 (1975) 229.

[34] R.H. Boyd, R.L. Christensen, R. Pua, J. Amer. Chem. Soc. 87 (1965) 3554.

[35] L.G. Radchenko, A.I. Kataigorodskii, Zh. Fiz. Khim. 48 (1974) 2702, Eng. edn. p. 1595.

[36] H.P. Diogo, M.E. Minas da Piedade, A.C. Fernandes, Martinho J.A. Simoes, M.A.V. Riberio da Silva, M.J.S. Monte, Thermochim. Acta 228 (1993) 15.

[37] J.S. Chickos, R.S. Annunziata, L.H. Ladon, A.S. Hyman, J.F. Liebman, J. Org. Chem. 51 (1986) 4311.

[38] K.L. Wolf, H. Weghofer, Z. Phys. Chem. 39(B) (1938) 194.

[39] K. Sasse, J. N'Guimbi, J. Jose, J.C. Merlin, Thermochim. Acta 146 (1989) 53.

[40] P.C. Hansen, C.A. Eckert, J. Chem. Eng. Data 31 (1986) 1.

[41] A. Aihara, Bull Chem. Soc. Jpn. 32 (1959) 1242.

[42] K. Rakus, S.P. Verevkin, J. Schaetzer, H.-D. Beckhaus, C. Rüchardt, Chem. Ber. 127 (1994) 1095.

[43] R. Sabbah, I. Antipine, Bull. Soc. Chim. Fr. (1987) 392.

[44] P.C. Hansen, C.A. Eckert, J. Chem. Eng. Data 31 (1986) 1.

[45] H. Hoyer, W. Peperle, Z. Electrochem. 62 (1958) 61.

[46] A.G. Osborn, D.R. Douslin, J. Chem. Eng. Data 20 (1975) 229.

[47] R. Jochems, H. Dekker, C. Mosselman, G. Somsen, J. Chem. Thermodyn. 14 (1982) 395, 799.

[48] T. Clark, T. Knox, H. Mackle, M.A. McKervey, J. Rooney, J. Chem. Soc. Faraday Trans. I 71 (1975) 2107.

[49] R.H. Boyd, S.N. Sanwal, S. Shary-Tehrany, D. McNally, J. Phys. Chem. 75 (1971) 1264.

[50] P.-J. Wu, L. Hsu, D.A. Dows, J. Chem. Phys. 54 (1971) 2714.

[51] M. Mansson, N. Rapport, E.F. Westrum Jr., J. Amer. Chem. Soc. 92 (1970) 7296.

[52] W.K. Bratton, I. Szilard, C.A. Cupas, J. Org. Chem. 32 (1967) 2019.

[53] B.F. Rordorf, Chemosphere 15 (1986) 1325.

[54] R. Bender, V. Bieling, G. Mauer, J. Chem. Thermodyn. 15 (1983) 585 .

[55] W. Brostow, D.M. McEachern, J.A. Valdez, Mater. Chem. 6 (1981) 187. 
[56] R.S. Dygdala, K. Stefanski, Chem. Phys. 53 (1980) 51.

[57] L.A. Torres-Gomez, G. Barreiro-Rodriguez, A. GalarzaMondragon, Thermochim. Acta 124 (1988) 229.

[58] J.C.R. Calado, A.R. Dias, M.E. Mina de Piedade, J.A. Martinho Simoes, Rev. Port. Quim. 22 (1980) 53; M.H.G.
Jacobs, P.J. van Ekeren, C.G. DeKruif, J. Chem. Thermodyn. 15 (1983) 619.

[59] A. VanKamp, Ph.D. Dissertation, Free University of Amsterdam, 1957.

[60] G. Borgen, J. Dale, J. Chem. Soc., Chem. Commun. 1340 (1970). 